\title{
Effect of Grain Size Distribution on Recrystallisation Kinetics in an Fe-30Ni Model Alloy
}

\author{
Mo Ji ${ }^{1, *}$, Claire Davis ${ }^{1}$ and Martin Strangwood ${ }^{2}$ (D) \\ 1 Warwick Manufacturing Group, University of Warwick, Coventry CV4 7AL, UK; \\ claire.davis@warwick.ac.uk \\ 2 School of Metallurgy and Materials, University of Birmingham, Birmingham B15 2TT, UK; \\ m.strangwood@bham.ac.uk \\ * Correspondence: m.ji.1@warwick.ac.uk; Tel.: +44-024-7652-3044
}

Received: 27 February 2019; Accepted: 21 March 2019; Published: 22 March 2019

\begin{abstract}
This paper discusses the role of grain size distribution on the recrystallisation rates and Avrami values for a Fe-30 wt. \% Ni steel, which was used as a model alloy retaining an austenitic structure to room temperature. Cold deformation was used to provide uniform macroscopic strain distributions (strains of 0.2 and 0.3 ), followed by recrystallisation during annealing at $850-950{ }^{\circ} \mathrm{C}$. It was shown that the Avrami parameter was directly related to the grain size distribution, with a lower Avrami exponent being seen for a larger average and wider grain size distribution. A method to predict the Avrami exponent from the grain size distribution was proposed. In situ heating in an SEM with EBSD showed the recrystallisation kinetics to be affected by differences in stored energy and nucleation in the different grain sizes supporting the proposed relationship.
\end{abstract}

Keywords: recrystallisation; grain size distribution; JMAK model; in situ EBSD

\section{Introduction}

A fine and uniform grain size is desirable in steels, to provide high strength and good toughness, and this requires recrystallisation during thermo-mechanical processing. It is important to be able to predict the rate of recrystallisation and a number of relationships, based on the Johnson-Mehl-Avrami-Kolmogorov (JMAK) equation, that has been reported. The Avrami exponent in the JMAK equation is a key parameter and is generally fitted to experimental data. Whilst the initial grain size has been shown experimentally to affect the Avrami exponent, no method to predict the Avrami exponent for a given grain size distribution has been reported previously.

Controlling recrystallisation during hot rolling or annealing after cold rolling is important in generating a fine and uniform grain size microstructure [1-5]. It has been widely accepted that recrystallisation primarily initiates in the heavily deformed material around grain boundaries, which is driven by the stored energy; and its reaction kinetics can be expressed as a function of the nucleation rate $\dot{N}$ and growth rate $\dot{G}[6-8]$. Thus, grain size and strain are two key parameters in predicting the recrystallisation kinetics. The classical model for recrystallisation kinetics is the sigmoidal time dependence of recrystallised volume fraction (JMAK model), where the recrystallised fraction $X$ can be expressed as:

$$
X=1-\exp \left(-k t^{n}\right)
$$

where, $k=\frac{f \dot{N} \dot{G}^{3}}{4}$ is the rate parameter ( $f$ is shape factor, $\frac{4 \pi}{3}$ for spherical nucleus) and $n$ is the Avrami exponent. The model assumes that the nucleation sites are randomly distributed and all nuclei grow isotropically at a constant rate [3]. 
The Avrami exponent $n$ is supposed to depend only on time for the nucleation and growth rate of recrystallisation (i.e., temperature independent); for example, Sellars reported that the exponent showed independence to temperature and strain rate [1]. Given the assumption of continuous or site saturated nucleation, and three-dimensional growth with a constant rate for recrystallisation, then the $n$ value should be four or three, respectively. However, the majority of published data give exponent values lower than two or even one $[2,3,9,10]$. Zaefferer et al. has investigated the recrystallisation kinetics in Fe-36Ni after cold deformation with an average grain size of $10 \mu \mathrm{m}$ and reported Avrami exponents between 1.06-1.38 [11]. Medina et al. and Laasraoui et al. examined microalloyed steels recrystallising at $1100-900{ }^{\circ} \mathrm{C}$ and reported that the $n$ value was lower than one with or without the influence of strain induced precipitation during recrystallisation [10,12]. Moreover, $n$ is in many cases not a constant value but decreases as recrystallisation progresses [13]. Recovery during recrystallisation has been suggested to be responsible for the low reported Avrami exponent values [3]. Additionally, for recovery occurring prior to recrystallisation, it would be expected to reduce the stored energy not modify the time-dependence of nucleation and growth. However, experiments have shown that low Avrami exponents can also be observed in the absence of any recovery [2]. Therefore, the Avrami exponent is not dependent on strain [1-3].

Some authors have proposed that variations in grain size and a heterogeneous distribution of stored energy can cause the low Avrami exponent values $[8,9,14]$. Hutchinson reported that under the same temperature and strain conditions, fine-grain sized copper (average grain size of $15 \mu \mathrm{m}$ ), gave an $n$ value of 2.7 whereas coarse-grain sized copper (average grain size of $50 \mu \mathrm{m}$ ) gave an $n$ value of 1.7 [15]. Similar observations have been reported by Barraclough and Sellars for Type 304 stainless steel, where the Avrami exponent decreased from 2 to 1 by increasing the initial average grain size from 140 to $530 \mu \mathrm{m}$ at 0.5 strain [1]. However, no grain size distribution nor the effect of the grain size distribution on the Avrami exponent was discussed in either case. Strain inhomogeneity has also been widely observed in deformed products; Furu observed that cold rolled aluminium was deformed inhomogeneously across thickness, the heavily deformed regions tend to recrystallise quicker than less deformed regions in aluminium, which leads to a faster initial recrystallisation rate and the rate decreases with time, i.e., lower Avrami exponent [3].

In the past 40 years, generally it has been the mode/average grain size values that have been considered in recrystallisation modelling. In practice, the initial microstructure includes a range of grain sizes, i.e., grain size distribution, and this is now being increasingly considered. Several authors have proposed models for recrystallisation inhomogeneity that takes the grain size distribution into consideration. The model used by Rehman and by Zurob et al. assumes that each grain has different stored energy after deformation dependent on its orientation/Taylor factor and its size, then the overall recrystallisation kinetics are predicted via subgrain growth modelling $[16,17]$. The model by Rollett predicts that larger grains have a less preferential nucleation site and/or less stored energy, thus, the larger grains recrystallise at a slower rate [8]. The recrystallisation nucleation and growth rate in each grain is expected to vary based on these models. The overall recrystallisation rate is the sum of the recrystallisation kinetics of each individual grain, therefore a decreasing recrystallisation growth rate is expected. However, no fitting parameters in these models have been developed to predict the Avrami exponent based on different grain size distribution. Additionally, very few experimental data of recrystallisation kinetics, i.e., starting and finishing time and Avrami exponent, has been linked to various grain size distributions to investigate its effect on the recrystallisation rate.

This paper reports a study on the recrystallisation kinetics at $850-950{ }^{\circ} \mathrm{C}$, following room temperature deformation to 0.3 and 0.2 strain, in a model Fe-30Ni steel with different starting grain size distributions and proposes a method to predict the Avrami exponent based on the starting grain size distribution. The Fe-30Ni steel is austenitic allowing the deformation structure and partially recrystallised austenitic microstructure to be observed at room temperature. In addition, in situ heating after deformation in a scanning electron microscopy (SEM) with electron backscattered 
diffraction (EBSD) was used to examine the effects of grain size distribution and strain heterogeneity on recrystallisation.

\section{Materials and Methods}

The material used in this work was a laboratory cast ingot of composition: $0.06 \mathrm{C}, 30.0 \mathrm{Ni}, 0.53 \mathrm{Mn}$, and $0.01 \mathrm{~S}$, all in wt. \% which was homogenised at $1100{ }^{\circ} \mathrm{C}$ for $30 \mathrm{~min}$ to remove any Mn segregation from solidification. Fe-30Ni steel has been used as a model alloy for recrystallisation studies by a number of authors [6,18-20] and it has been shown that the dislocation structures produced after cold deformation are comparable with those seen after hot deformation in this material, yet it is worth noting that the stored energy from room temperature imposed will not be the same as the same strain at high temperature [11,21]. Additionally, differences in recovery can arise between cold deformed and annealed (recovery occurring on heating to the annealing temperature) and hot deformed (dynamic recovery prior to recrystallisation) samples, however, it has been reported that recovery prior to recrystallisation does not affect the recrystallisation kinetics (Avrami exponent), which was being considered in this paper, although it would affect the recrystallisation start and finish times [2].

Specimens of $10 \mathrm{~mm}$ in diameter and $15 \mathrm{~mm}$ in height were machined from the homogenized slab and then reheated to $1100{ }^{\circ} \mathrm{C}$ and $1300^{\circ} \mathrm{C}$ for 30 and 5 min respectively to relieve any residual stress and to provide different starting grain size distributions for the deformation trials. The specimens were deformed to 0.2 or 0.3 strain at room temperature by uniaxial compression, using a Instron 3300 series static testing machine (Instron, Norwood, MA, USA), lubricated by PTFE film with a strain rate of $2 / \mathrm{min}$, before being reheated to $950{ }^{\circ} \mathrm{C}, 900{ }^{\circ} \mathrm{C}$ or $850{ }^{\circ} \mathrm{C}$ for various times to give partial and full recrystallisation, followed by quenching into water. No barrelling was observed for the cold deformed samples. The heat-treated and deformed specimens were sectioned, mounted in Bakelite and ground, polished and etched with Kallings reagent to reveal the austenite grain structures. Microhardness tests were carried out on a Struers DuraScan Micro-hardness tester (Struers ApS, Ballerup, Denmark) using a $0.5 \mathrm{~kg}$ load. The mapping area was $3.5 \mathrm{~mm} \times 7 \mathrm{~mm}$ with a step size of $0.5 \mathrm{~mm}$. The recrystallisation fraction was determined by point counting from optical images. EBSD samples were prepared using a VibroMet 2 Vibratory Polisher (Buehler, Lake Bluff, IL, USA) with Buehler MasterMet 2 Colloidal Silica for two hours after general polishing to remove any deformation induced during the polishing procedure. EBSD was performed on a ZEISS SIGMA FEG-SEM with Nordlys EBSD detector (Carl Zeiss, Oberkochen, Germany) and samples were mounted onto a GATAN in situ heating stage (capable of heating to $700{ }^{\circ} \mathrm{C}$ ); the sample size was $5 \mathrm{~mm}$ square and $1 \mathrm{~mm}$ thick. The EBSD step size was $0.7 \mu \mathrm{m}$ and the local misorientation (between 0 and 5 degrees, point to point using a filter size of $3 \times 3$ pixels) was calculated by CHANNEL 5 software (Version 5, Oxford Instrument, Oxford, UK).

The initial grain size distributions (equivalent circle diameter, ECD) of the heat treated samples can be seen in Figure 1. The fine-grained specimen had a mode grain size of $100 \mu \mathrm{m}$ with an area fraction of 0.32 and $95 \%$ of grains were sized between 60 and $160 \mu \mathrm{m}$. The coarse-grained specimen had a mode grain size of $160 \mu \mathrm{m}$, with an area fraction of 0.12 , and $95 \%$ of grains were sized between 60 and $320 \mu \mathrm{m}$.

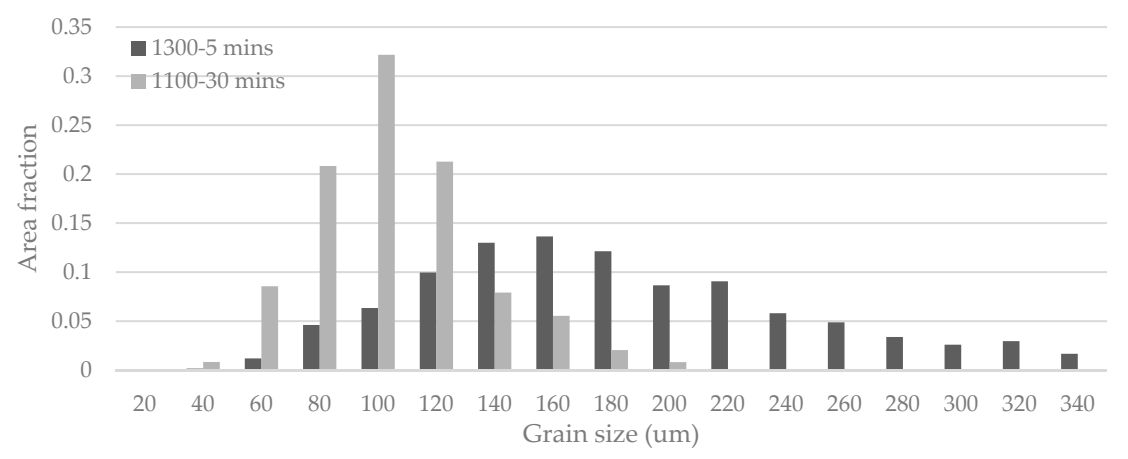

Figure 1. Grain size distribution for the heat-treated samples. 


\section{Results}

\subsection{As-Cold Deformed Microstructure}

The specimen with mode grain size of $160 \mu \mathrm{m}$ deformed at 0.3 strain was used to examine the effect of grain size on local strain distribution. First, the presence of any macroscopic strain variability needed to be determined as Luo et al. reported an effect of macroscopic strain distributions on lowering the Avrami exponents [17]. Figure 2 shows microhardness mapping of the initial (homogenised) and deformed samples, where no systematic variation in hardness can be seen with position, which indicated that there was no significant macroscopic strain distribution, as expected from the lack of barreling for the deformed compression samples. Therefore, any differences in measured Avrami exponent between the samples would not be related to macroscopically varying strain affecting recrystallisation rates. The step size for the microhardness test was $500 \mu \mathrm{m}$, which was larger than the maximum grain size of the homogenised samples and the typical indent size was approximately $100 \mu \mathrm{m}$ at $0.5 \mathrm{~kg}$ load, therefore, any local strain inhomogeneity within grains or across grain boundaries would not be revealed.

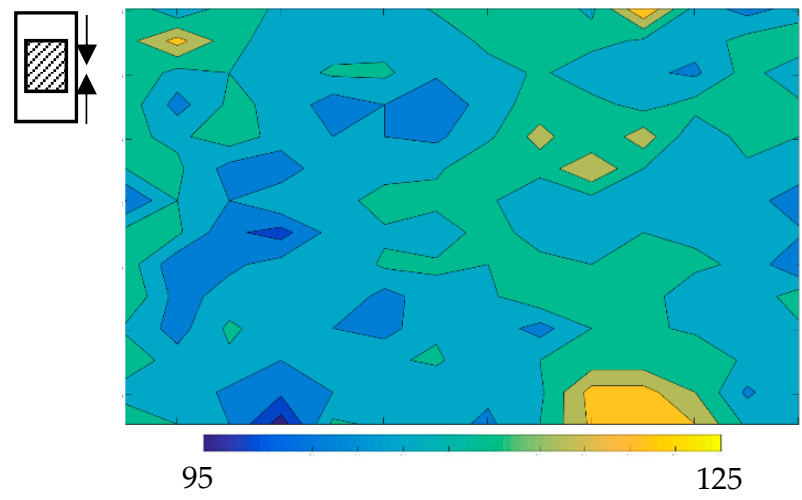

(a)

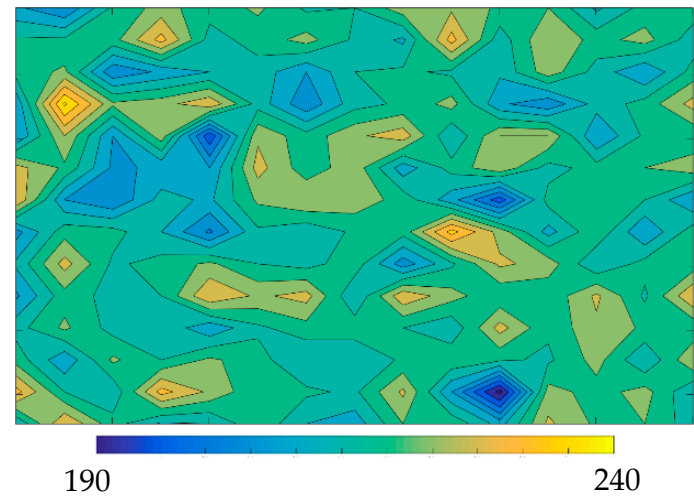

(b)

Figure 2. Microhardness mapping of Fe-30Ni material in (a) homogenized and (b) deformed to 0.3 strain at room temperature conditions, step size $0.5 \mathrm{~mm}$. (Examination area $3.5 \mathrm{~mm} \times 7 \mathrm{~mm}$ ). Inset diagram: Arrows show the compression direction for the $15 \mathrm{~mm}$ height; $10 \mathrm{~mm}$ diameter samples and the shadowed region shows the examination area.

EBSD scanning was carried out to characterise the strain distribution on a microscopic scale. Local misorientation can be used as an indication of the stored energy because misorientation increases with increasing dislocation density [2]. The local misorientation map shown in Figure 3 clearly shows that the deformation structure was inhomogeneous within each individual grain and among different grains. Higher local misorientation had been observed in the grain boundary regions than the grain interiors. This agreed with the observation of other cold deformed metals, such as aluminum and copper [22]. These heavily deformed regions will then promote recrystallisation nucleation, and the initial growth rate was expected to be high around these regions: In Figure 3, the coarse grain on the right of the micrograph shows low local misorientation, whereas the finer grains on the left show significantly higher local misorientation attributed to the higher grain boundary length per unit area. The regions with higher grain boundary length per unit area, i.e., finer grains, were expected to have a higher recrystallisation rate attributed to both the higher number of potential nucleation sites and higher average stored energy level (assuming recrystallisation nucleation at grain boundaries). No shear bands were observed for the 0.2 or 0.3 cold deformed samples. 


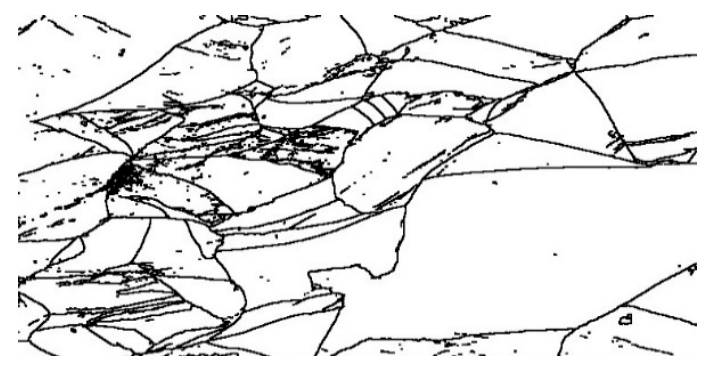

(a)

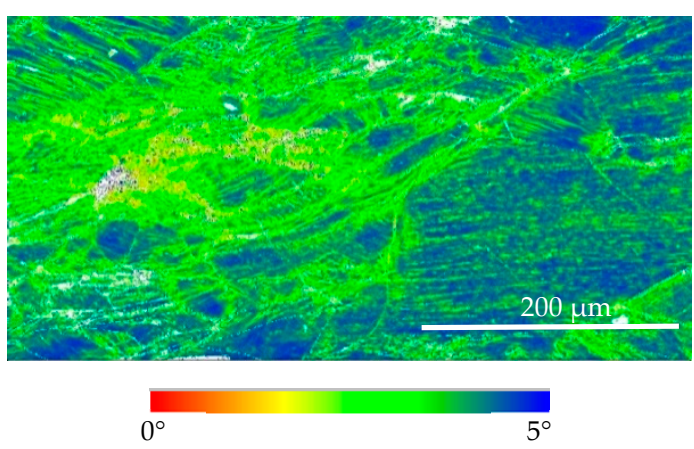

(b)

Figure 3. EBSD (electron backscattered diffraction) image of Fe-30Ni sample with initial mode grain size of $160 \mu \mathrm{m}$ deformed to 0.3 strain at room temperature (a) grain boundary (HAGB > 15 degree) and (b) local misorientation map (misindexing, i.e., white regions, were assumed to be heavily deformed).

\subsection{Recrystallisation Kinetics Determination}

The recrystallisation kinetics for the Fe-30Ni steel with an initial mode grain size of $160 \mu \mathrm{m}$ is shown in Figure 4 and for the Fe-30Ni steel with an initial mode grain size of $100 \mu \mathrm{m}$ in Figure 5, as well as the double log normal of recrystallisation fraction versus log normal time for the different temperatures and strains. These plots were used to obtain the value for the Avrami exponent $n$ and the parameter $k$ for the JMAK equation. Linear plots have been observed for all conditions, which indicated that the recrystallisation nucleation and growth mechanisms had not changed during the recrystallisation process at the different strains and temperatures.

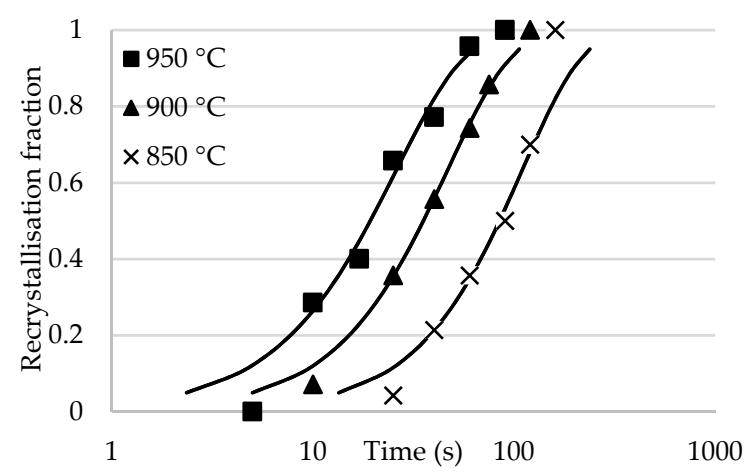

(a)

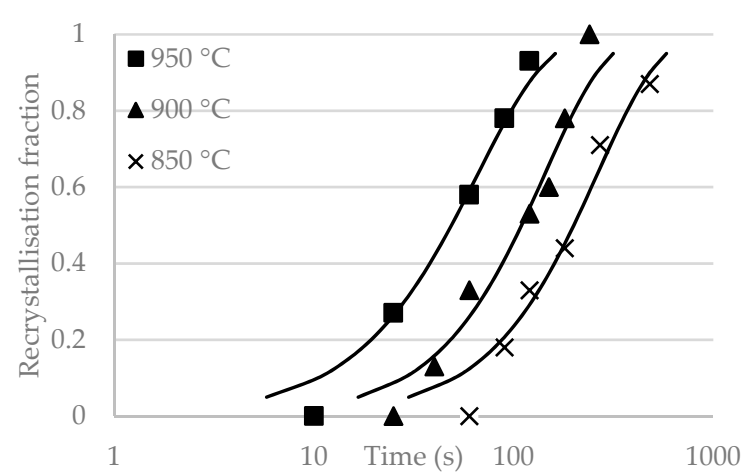

(c)

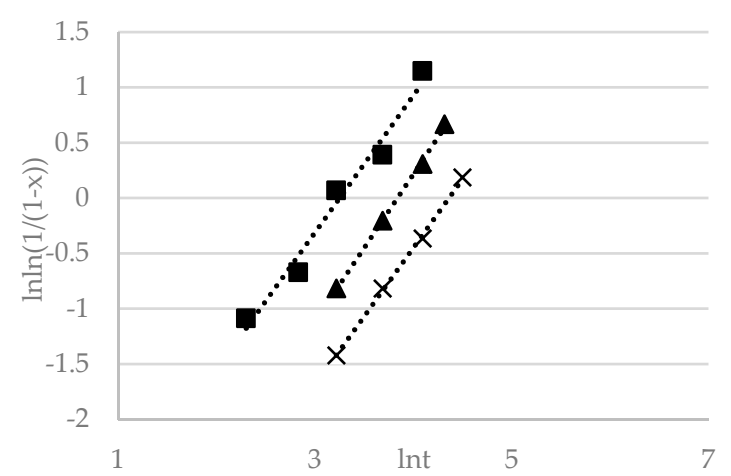

(b)

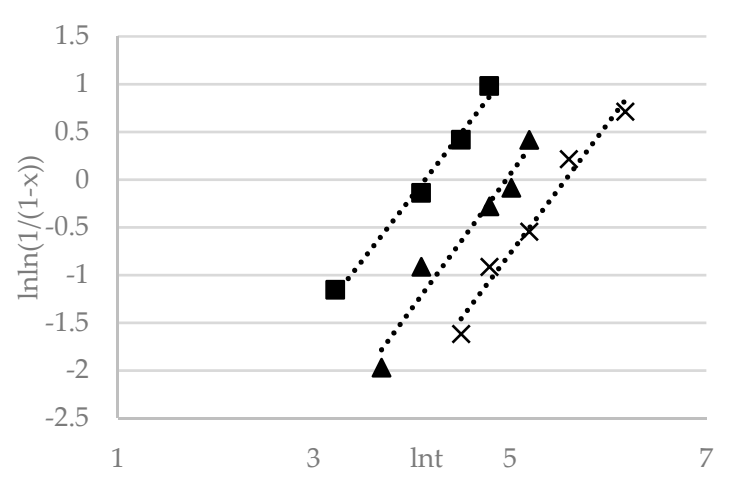

(d)

Figure 4. Recrystallisation kinetics and double log diagram for $160 \mu \mathrm{m}$ mode grain size samples deformed to $(\mathbf{a}, \mathbf{b}) 0.3$ strain and $(\mathbf{c}, \mathbf{d}) 0.2$ strain at room temperature, then annealed at three temperatures $\left(850,900\right.$ and $\left.950{ }^{\circ} \mathrm{C}\right)$. 


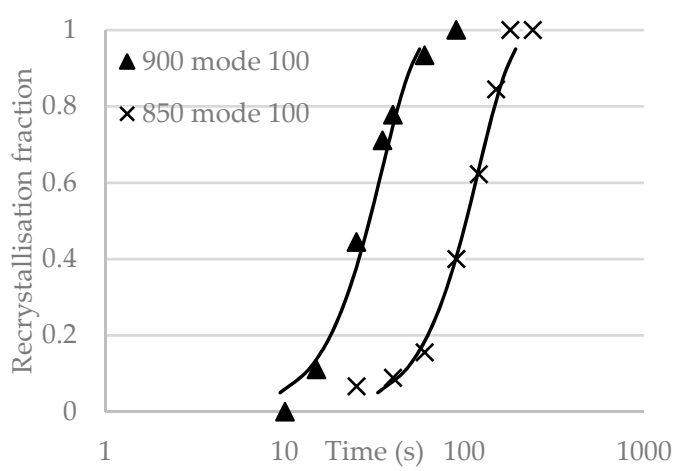

(a)

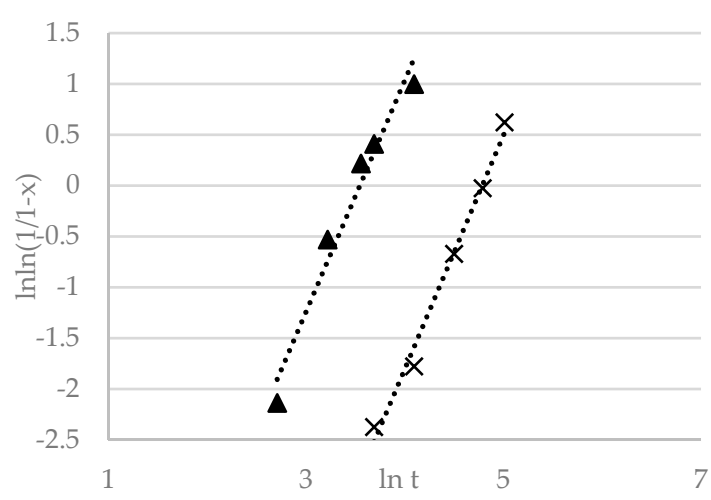

(b)

Figure 5. Recrystallisation kinetics (a) and double log diagram (b) for $100 \mu \mathrm{m}$ mode grain size samples deformed to 0.2 strain at room temperature, then held at two temperatures $\left(850\right.$ and $\left.900{ }^{\circ} \mathrm{C}\right)$.

JMAK curves were fitted to the experimental recrystallisation fraction data, which was obtained from the partially recrystallised samples. It can be seen that, for the $160 \mu \mathrm{m}$ mode grain size specimens, recrystallisation starting and finishing times were approximately five times slower for the lower strain value, and, at all temperatures and strains, the Avrami exponent, $n$, values were between 1.2 and 1.4 (Table 1). The results indicated that the $n$ value for Fe-30Ni was relatively constant for recrystallisation in this temperature range after 0.2-0.3 strain, which agreed with experimental data obtained by Abdullah-Zadeh [23]. For the $100 \mu \mathrm{m}$ mode grain size specimen after deformation to 0.2 strain, the Avrami exponent was 2.3, which was considerably higher than for the $160 \mu$ mode grain size sample. The difference in Avrami exponent was comparable to the results on fine-/coarse-grained copper reported by Hutchinson with average grain sizes of 15 and $50 \mu \mathrm{m}$ [15]. From the 0.2 and 0.3 strain test results, it could be seen that increasing strain did not lead to a higher Avrami exponent, consistent with literature results [11,24]. That is, a higher Avrami exponent had been observed for the samples with a tighter grain size distribution (mode grain size $100 \mu \mathrm{m}$ ) compared to the samples with a wider grain size distribution (mode grain size $160 \mu \mathrm{m}$ ) under the same condition, i.e., strain 0.2, temperature range $900-850{ }^{\circ} \mathrm{C}$. In addition, the Avrami exponents measured were significantly lower than the theoretical value for site saturation nucleation and three-dimensional linear growth, i.e., $n=3$, in all cases.

Table 1. Summary of experimentally determined Avrami exponents.

\begin{tabular}{cccc}
\hline Temperature $\left({ }^{\circ} \mathbf{C}\right)$ & Mode Grain Size $(\boldsymbol{\mu m})$ & Strain & $\boldsymbol{n}$ Value \\
\hline 950 & 160 & 0.3 & 1.2 \\
900 & 160 & 0.3 & 1.3 \\
850 & 160 & 0.3 & 1.4 \\
950 & 160 & 0.2 & 1.3 \\
900 & 160 & 0.2 & 1.4 \\
850 & 160 & 0.2 & 1.3 \\
900 & 100 & 0.2 & 2.3 \\
850 & 100 & 0.2 & 2.3 \\
\hline
\end{tabular}

\subsection{Microstructure Evolution during Recrystallisation}

Figure 6 shows optical images of the grain structures for the initial $160 \mu \mathrm{m}$ material after various annealing times at $850{ }^{\circ} \mathrm{C}$ after deformation to 0.3 strain. Non-, partial- and fully-recrystallised microstructures are shown. The variation in recrystallisation growth rate in the different grain sizes is clearly shown in Figure $6 \mathrm{~b}$ after annealing for $40 \mathrm{~s}$, since the grain boundaries had a significantly higher number of recrystallised grains than the matrix interior, as indicated by arrows. This agreed with the literature that the preferred recrystallisation nucleation sites were twin boundaries and grain 
boundaries $[3,7,25]$. Additionally, it can be seen from Figure $6 \mathrm{c}$ that the grains over $200 \mu \mathrm{m}$ were still shown as being predominantly unrecrystallised at $850^{\circ} \mathrm{C}$ for $90 \mathrm{~s}$. That is, even though recrystallisation had occurred along the grain boundary regions in the coarse grains $(>200 \mu \mathrm{m})$ and the deformed coarse grains were being consumed during recrystallisation, the recrystallisation growth was still at a slower rate in the coarse grains attributed to the lower stored energy as well as the lower grain boundary per unit area. Therefore, it was expected that all the fine grains must have recrystallised prior to the coarse grains. The final micrograph, Figure $6 \mathrm{~d}$ shows the fully recrystallised microstructure.

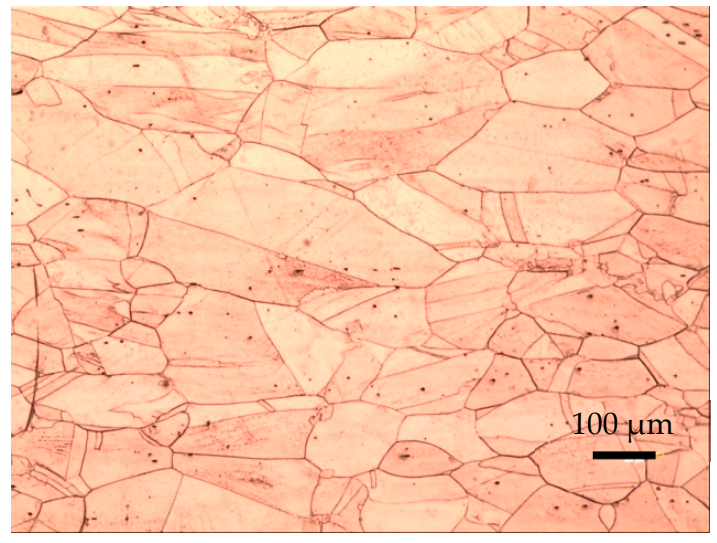

(a)

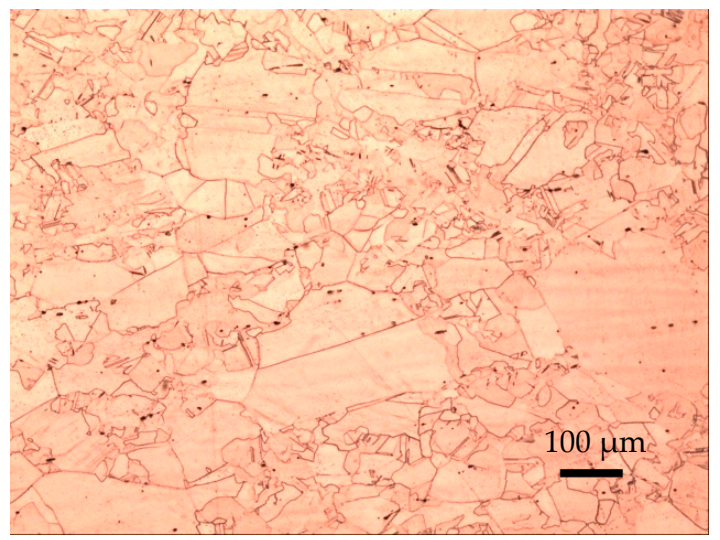

(c)

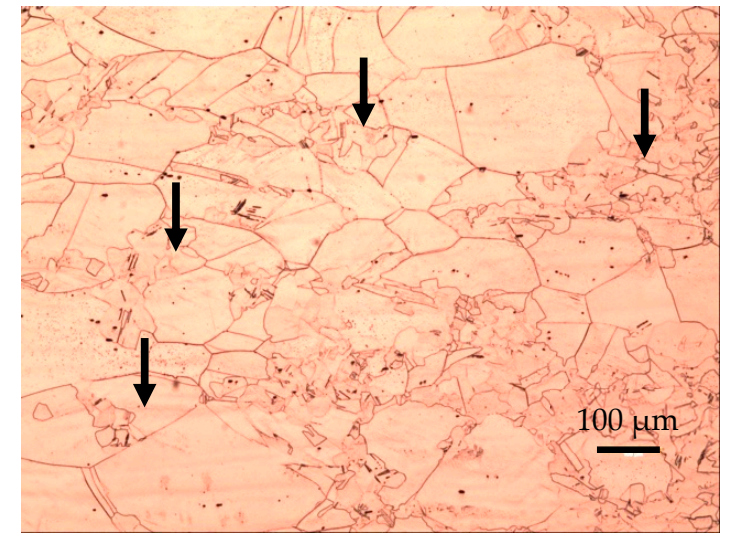

(b)

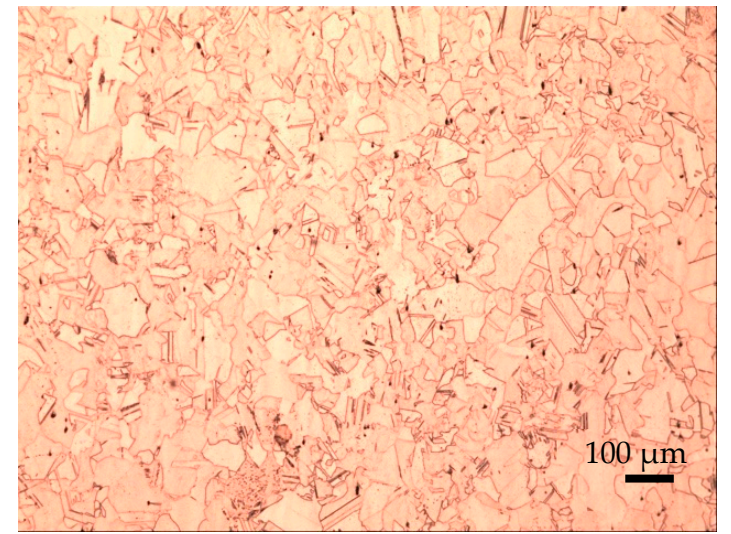

(d)

Figure 6. Microstructure evolution in the $160 \mu \mathrm{m}$ initial grain size material at (a) $25 \mathrm{~s}$, unrecrystallised; (b) 40 s, 20\% recrystallised; (c) 90 s, 50\% recrystallised; and (d) $160 \mathrm{~s}$, fully recrystallised at $850{ }^{\circ} \mathrm{C}$, 0.3 strain. The arrows in (b) show recrystallisation nuclei preferentially located at grain boundaries and triple points.

Grain size distribution evolution during recrystallisation was also examined to reveal the recrystallisation rate for the different grain sizes in the original distribution. If a partially recrystallised grain size distribution showed a comparable grain size distribution to the original distribution for the coarser grain size range, then this indicated that the coarse grains, statistically speaking, had not recrystallised whilst the finer grains had. Figure 7 shows the grain size distribution evolution for the initial grain size distribution with mode grain size of $160 \mu \mathrm{m}$ and the distributions after holding at $850{ }^{\circ} \mathrm{C}$ for $40 \mathrm{~s}$ (partially recrystallised, 20\%), $90 \mathrm{~s}$ (partially recrystallised, $50 \%$ ) and $160 \mathrm{~s}$ (fully recrystallised). It can be seen that the shape of the distributions, which, for both $40 \mathrm{~s}$ and $90 \mathrm{~s}$ hold, were bimodal not unimodal and, for the $40 \mathrm{~s}$, followed the shape of the starting distribution for the 220 to $280 \mu \mathrm{m}$ size classes. This strongly suggested that the coarser grains were recrystallising at a considerably slower rate compared to the finer grains during the early stage of recrystallisation. Additionally, the area fraction of grains in the grain size range over $220 \mu \mathrm{m}$ at $40 \mathrm{~s}$ 
was $24 \%$ compared to $34 \%$ in the initial condition, and grains over $200 \mu \mathrm{m}$ were detected at $90 \mathrm{~s}$ although coarse. The fewer coarser grains in this case could be due to a lack of statistical sampling at the extremes of the distribution, although over $200 \mu \mathrm{m}$ grains were measured to generate the distribution, but it is more likely that this could be due to the coarser grains being decreased in size as the recrystallising grains nucleated from adjacent grains, or recrystallisation nuclei at the onset of recrystallisation in these coarse grains grew into the grain interior (as seen in Figures 6 and 8). Nevertheless, the area fraction for the finer grain size range, $20-80 \mu \mathrm{m}$, increased significantly from $7 \%$ (initial condition) to $41 \%$ (40 s annealing time). In addition, the area fraction of the grain size ranged between 100-200 $\mu \mathrm{m}$, which decreased. This suggests that recrystallisation mainly occurred in the grain size range up to $200 \mu \mathrm{m}$, with the coarser grains, i.e., $>200 \mu \mathrm{m}$, not recrystallising in the early stages of overall recrystallisation.

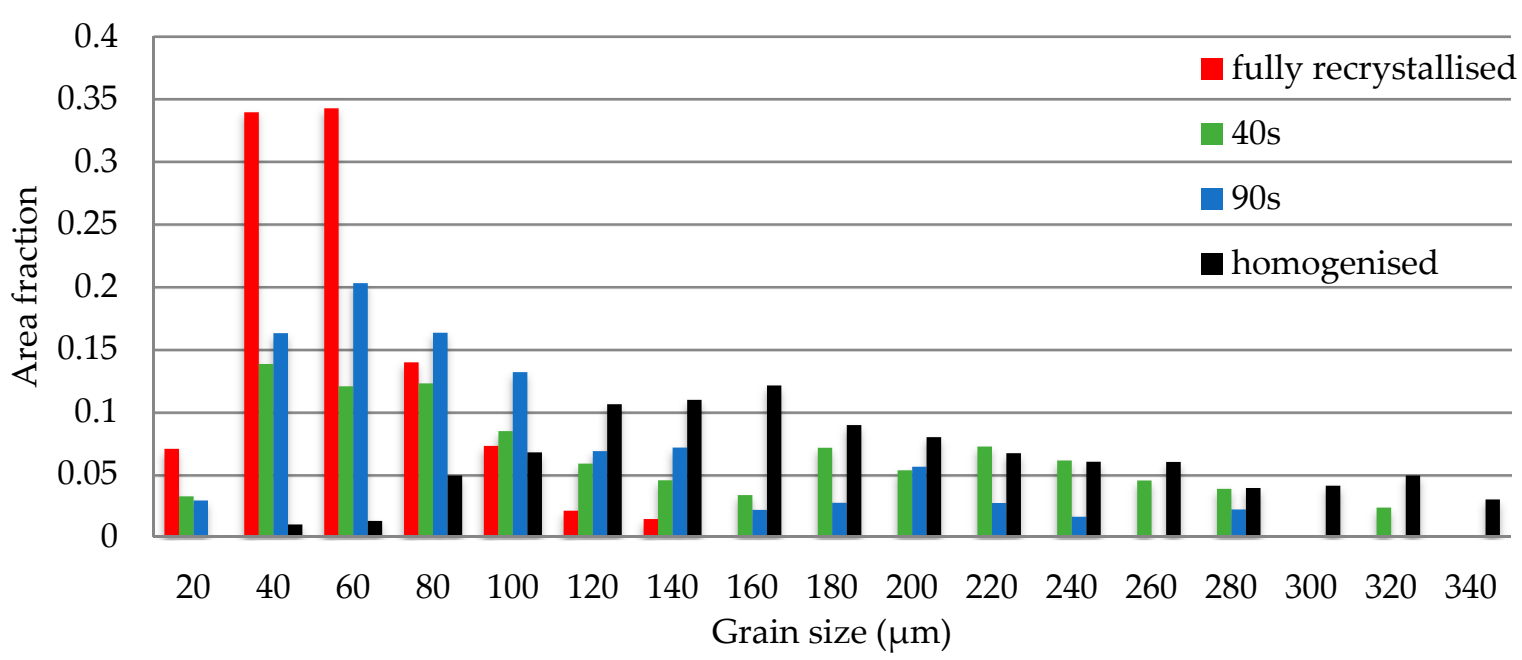

Figure 7. The grain size distribution of homogenised, $40 \mathrm{~s}$ (30\% recrystallised), $90 \mathrm{~s}$, (50\% recrystallised) and fully recrystallised samples.

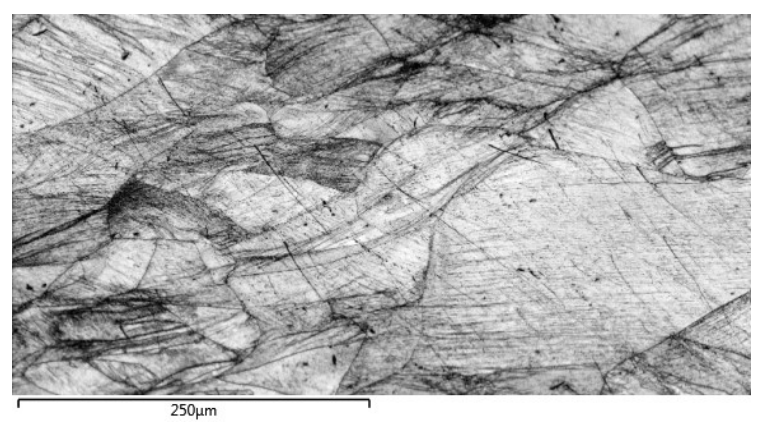

(a)

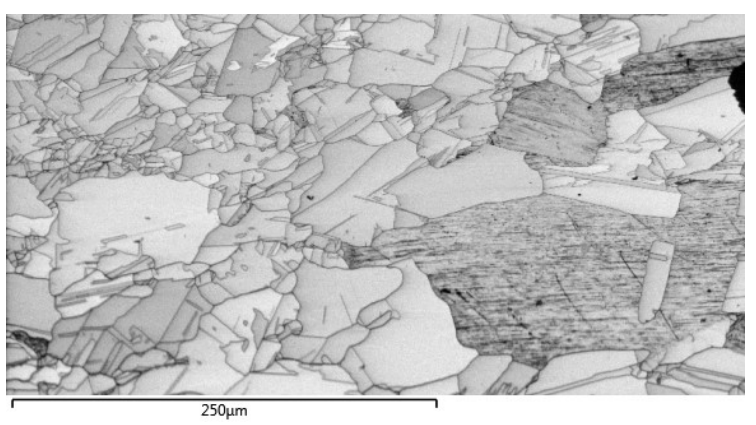

(b)

Figure 8. Band contrast EBSD images for the (a) cold deformed sample with $160 \mu \mathrm{m}$ mode gran size (0.3 strain) and (b) partially recrystallised sample after reheating at $700{ }^{\circ} \mathrm{C}$ for $60 \mathrm{~min}$ showing the coarse grain remains unrecrystallised whilst the fine grain region recrystallised.

Figure 8 shows the EBSD band contrast map after cold deformation (a) and after 60 min (b) at $700{ }^{\circ} \mathrm{C}$ for the material with an initial mode grain size of $160 \mu \mathrm{m}$. Note that a lower temperature was used to allow the in situ recrystallisation to be observed, hence requiring longer annealing times, but the recrystallisation mechanism and Avrami exponent are known to be temperature independent [1]. The same area showing the deformed microstructure is shown in Figure 3. Figure 8 shows that the coarse grain on the right side of the image had not fully recrystallised after 60 min, whereas the finer grains had completed recrystallisation. That is, finer grains recrystallised considerably faster than 
the coarser grains, which was attributed to both higher preferential nucleation sites density and the higher average stored energy. Additionally, some of the grain boundary area had been consumed by recrystallised grains (growing into the grain interior).

\section{Discussion}

For each individual grain that deformed to 0.3 or 0.2 strain (with no shear band formation), recrystallisation occurred at the grain boundaries and the recrystallised grains grew into the grain interior. As a result, finer grains in the distribution recrystallised quicker, which was attributed to a larger number of nucleation sites per unit area, and coarser grains recrystallised more slowly. It was shown in both optical microscopy, Figure 7, and EBSD, Figure 8, that the recrystallisation rates were different for the different grain size classes in a distribution. Additionally, the early impingement of the recrystallisation nuclei could also have led to the decrease in the Avrami exponent, which was attributed to the preferred nucleation along the grain boundary regions.

To quantitatively demonstrate how a grain size distribution affects the recrystallization kinetics, and hence the Avrami exponent, it was assumed that each grain separately followed the JMAK model, in which site saturation and three-dimensional constant growth rate occurred, giving an $n$ value of 3 . The assumption was based on the fact that recrystallisation nuclei pre-exist in the deformed microstructure without continued nucleation along grain boundaries after the initial nucleation event, and that recrystallised grain growth is not inhibited by precipitates or second phase particles. The recrystallisation kinetics for each individual grain were then calculated using the Sellars approach [1]. The grain size and strain exponents were taken as 2 and -4 respectively. Then, the recrystallisation starting time was given as,

$$
R_{\mathrm{s}}=A \cdot D_{0}^{2} \varepsilon^{-4} \exp \left(\frac{Q}{R T}\right)
$$

where $A$ is a constant, $D_{0}$ is the initial grain size, $\varepsilon$ is the strain, $Q$ is the recrystallisation activation energy, $R$ is the gas constant and $T$ is the isothermal holding temperature.

Assuming each grain size class recrystallises individually, then the recrystallisation curve should roughly follow the cumulative area fraction curve resulting from the application of Equation (2) to the grain size distribution, Figure 9, for a given holding time.

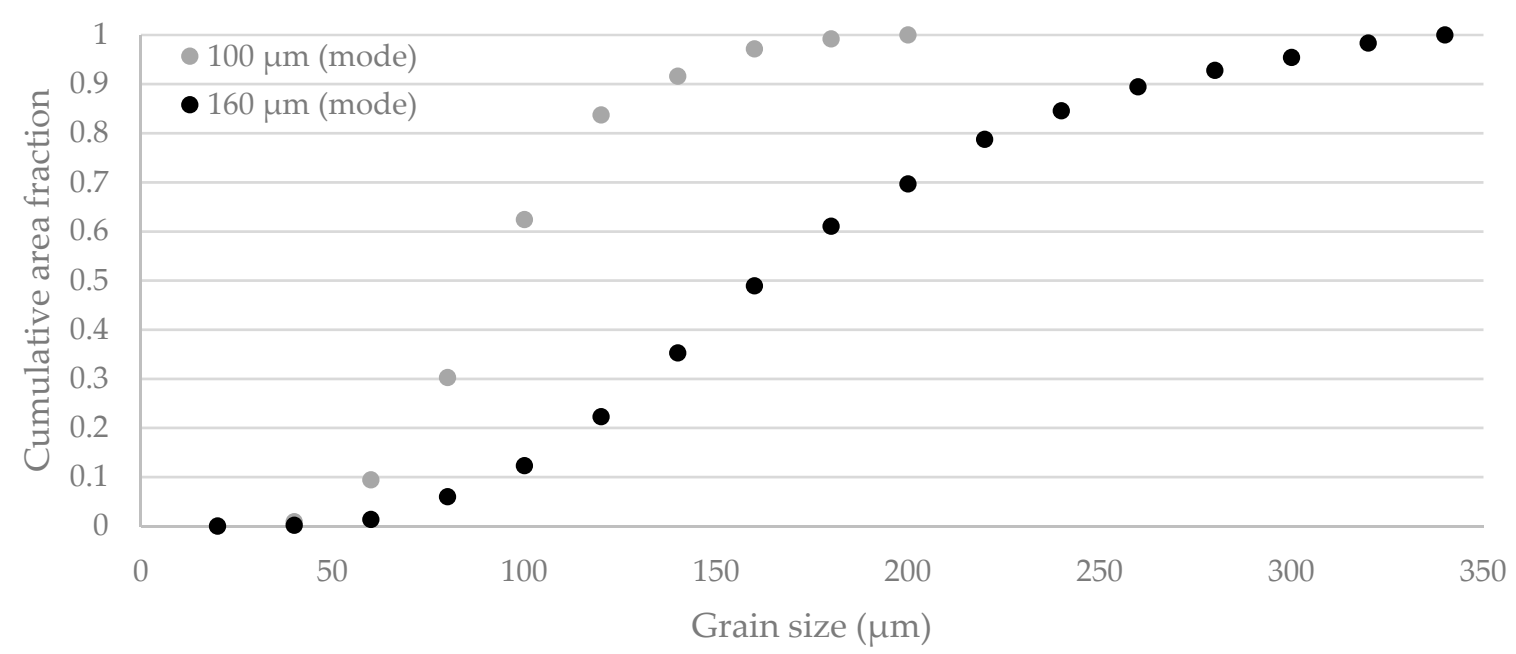

Figure 9. Cumulative area fraction representation of grain size for the two different grain size distributions. 
The Avrami exponent was experimentally measured as:

$$
n=\frac{\ln \left(\ln \left(\frac{1}{1-X(t)}\right)\right)}{\ln (t)}
$$

where $X(t)$ is the recrystallisation fraction at time $t$.

Assuming each grain size class recrystallises individually, then the time to achieve 5\% $\left(R_{0.05}\right)$ and $85 \%\left(R_{0.85}\right)$ of the overall recrystallised fraction was approximately equal to the recrystallisation starting time for $D_{0.05}$ and $D_{0.85}$, where $D_{0.85}$ and $D_{0.05}$ was the grain size class at $85 \%$ and $5 \%$ of the cumulative grain size distribution respectively, as shown in Figure 9.

Therefore, the Avrami exponent could be estimated as,

$$
n=\frac{\ln \left(\ln \left(\frac{1}{1-0.85}\right)\right)-\ln \left(\ln \left(\frac{1}{1-0.05}\right)\right)}{\ln \left(R_{0.85}\right)-\ln \left(R_{0.05}\right)}
$$

As recrystallisation time is proportional to the square of grain size, as shown in Equation (2), then Equation (4) can be given as,

$$
n=\frac{\ln \left(\frac{\ln \left(\frac{1}{1-0.85}\right)}{\ln \left(\frac{1}{1-0.05}\right)}\right)}{\ln \left(\frac{R_{0.85}}{R_{0.05}}\right)}=\frac{3.6}{\ln \left(\frac{D_{0.85}}{D_{0.05}}\right)^{2}}
$$

For the samples with mode grain size of $160 \mu \mathrm{m}$, the equation predicted the Avrami exponent as 1.5 and 2.1 for the mode grain size of $100 \mu \mathrm{m}$ using the grain sizes from Figure 9. The results showed the same trend as the experimental results (Table 1) with the smaller average and narrower grain size distribution showing a significantly lower Avrami exponent than for the larger average, wider grain size distribution. Additionally, it is worth noting that this approach had only considered a low strain condition, i.e., up to 0.3 strain, without the interference of the shear bands, therefore it may not have been applicable for the recrystallisation kinetics prediction after severe cold deformation. However, the measured Avrami exponents were slightly higher for the coarser grained material, and lower for the finer grained samples than predicted and this requires further consideration. Nevertheless, this approach provides the first attempt to quantitatively predict the Avrami exponent for a material based on the initial grain size distribution and is consistent with the reported experimental variations in Avrami exponent reported in the literature for different grain size samples.

\section{Conclusions}

The effect of initial grain size distribution on the recrystallisation kinetics, in particular the Avrami exponent, has been determined using a model Fe-30Ni austenitic steel. Room temperature deformation to 0.2 and 0.3 strain followed by recrystallisation at $850-950{ }^{\circ} \mathrm{C}$ for samples with different initial grain size distributions ('fine' with mode grain size of $100 \mu \mathrm{m}$ and 'coarse' with mode grain size of $160 \mu \mathrm{m}$ ) was examined. The Avrami exponents were measured to be between 1.2-1.4 for samples with the coarse mode grain size and 2.3 for samples with a fine mode grain size. The Avrami exponent was found to be independent of the strain and temperature. The different Avrami exponents observed for the samples were found to be due to the heterogeneity of recrystallisation rates among the different grain size classes, with fine grains having a higher stored energy and more nucleation sites per unit area (higher grain boundary area) and therefore recrystallised more quickly than the coarser grains. Therefore, the grain size distribution plays an important role in recrystallisation kinetics and needs to be taken into consideration when predicting recrystallisation kinetics. A method to predict the Avrami exponent from the grain size distribution was proposed for low strain deformation conditions, i.e., 
up to 0.3 strain, with a higher Avrami exponent being predicted for a larger average and wider grain size distribution in line with the experimental observations.

Author Contributions: Conceptualization, M.J., C.D. and M.S.; methodology, M.J.; validation, M.J., C.D. and M.S.; formal analysis, M.J., C.D. and M.S.; investigation, M.J.; resources, C.D.; data curation, M.J.; writing-original draft preparation, M.J.; writing-review and editing, C.D. and M.S.; visualization, M.J.; supervision, C.D. and M.S.; project administration, C.D.; funding acquisition, C.D. and M.S.

Funding: This research was funded by EPSRC and Tata Steel Europe.

Acknowledgments: The authors would like to thank WMG at the University of Warwick for the provision of research facilities, and Tata Steel Europe for the provision of test material, data support of the project.

Conflicts of Interest: The authors declare no conflict of interest.

\section{References}

1. Barraclough, D.R.; Sellars, C.M. Static recrystallization and restoration after hot deformation of type 304 stainless steel. Met. Sci. 1979, 13, 257-268. [CrossRef]

2. Humphreys, F.J.; Hatherly, M. Recrystallisation and Related Annealing Phenomena, 2nd ed.; Elsevier: Oxford, UK, 2004.

3. Furu, T.; Marthinsen, K.; Nes, E. Modelling recrystallisation. Mater. Sci. Technol. 1990, 6, $1093-1102$. [CrossRef]

4. Park, J.T.; Szpunar, J.A. Effect of initial grain size on texture evolution and magnetic properties in non-oriented electrical steels. J. Magn. Magn. Mater. 2009, 321, 1928-1932. [CrossRef]

5. Burger, G.B.; Gupta, A.K.; Jeffrey, P.W.; Lloyd, D.J. Microstructural control of aluminum sheet used in automotive applications. Mater. Charact. 1995, 35, 23-29. [CrossRef]

6. Cizek, P.; Bai, F.; Palmiere, E.J.; Rainforth, W.M. EBSD study of the orientation dependence of substructure characteristics in a model $\mathrm{Fe}-30 \mathrm{wt} \% \mathrm{Ni}$ alloy subjected to hot deformation. J. Microsc. 2005, 217, 138-151. [CrossRef] [PubMed]

7. Rios, P.R.; Siciliano, F., Jr.; Sandim, H.R.Z.; Plaut, R.L.; Padilha, A.F. Nucleation and growth during recrystallisation. Mater. Res. 2005, 8, 225-238. [CrossRef]

8. Rollett, D.; Srolovitz, D.J.; Doherty, R.D.; Anderson, M.P. Computer simulation of recrystallization in non-uniformly deformed metals. Acta Metall. 1989, 37, 627-639. [CrossRef]

9. Saidi, P.; Shahandeh, S.; Hoyt, J.J. Relationship between recrystallization kinetics and the inhomogeneity of stored energy. Metall. Mater. Trans. A 2015, 46, 2975-2985. [CrossRef]

10. Medina, S.F.; Quispe, A. Improved model for static recrystallisation kinetics of hot deformed austenite in low alloys and $\mathrm{Nb} / \mathrm{V}$ microalloyed steels. ISIJ Inter. 2001, 41, 774-781. [CrossRef]

11. Zaefferer, S.; Baudin, T.; Penelle, R. A study on the formation mechanisms of the cube recrystallization texture in cold rolled Fe- 36\% Ni alloys. Acta Mater. 2001, 49, 1105-1122. [CrossRef]

12. Laasraoui, A.; Jonas, J.J. Prediction of temperature distribution, flow stress and microstructure during the multipass hot rolling of steel plate and strip. Trans. Iron Steel Inst. Japan 1991, 31, 95-105. [CrossRef]

13. Sellars, C.M. The Physical Metallurgy of Hot Working. In Proceedings of the an International Conference on Hot Working and Forming Processes, London, UK, 14-15 July 1980; pp. 3-15.

14. Luo, H.; Sietsma, J.; van der Zwaag, S. Effect of inhomogeneous deformation on the recrystallization kinetics of deformed metals. ISIJ Inter. 2004, 44, 1931-1936. [CrossRef]

15. Hutchinson, B.; Jonsson, S.; Ryde, L. On the kinetics of recrystallisation in cold worked metals. Scr. Metall. 1989, 23, 671-676. [CrossRef]

16. Cram, D.G.; Zurob, H.S.; Brechet, Y.J.M.; Hutchinson, C.R. Modelling discontinuous dynamic recrystallisation using a physical based model for nucleation. Acta Mater. 2009, 57, 5218-5228. [CrossRef]

17. Rehman, M.K. Modelling the Microstructure Evolution during Hot Deformation of Microalloyed Steels. Ph.D. Thesis, McMaster University, Hamilton, ON, Canada, November 2014.

18. Cizek, P.; Whiteman, J.A.; Rainforth, W.M.; Beynon, J.H. EBSD and TEM investigation of the hot deformation substructure characteristics of a type 316L austenitic stainless steel. J. Microsc. 2004, 213, 285-295. [CrossRef] [PubMed] 
19. Black, M.P. Microstructural evolution of austenite in a microalloyed Fe-30Ni alloy. Ph.D. Thesis, University of Sheffield, Sheffield, UK, 2002.

20. Palmiere, E.J. The use of model systems based on $\mathrm{Fe}-30 \mathrm{wt} \% \mathrm{Ni}$ for investigating the precipitation and transformation behaviour of microalloyed austenite. In HSLA Steels 2015, Microalloying 2015 E Offshore Engineering Steels 2015; Springer: New York, NY, USA, 2016; pp. 1095-1101.

21. Poddar, D.; Cizek, P.; Beladi, H.; Hodgson, P.D. Evolution of strain-induced precipitates in a model austenitic Fe-30Ni-Nb steel and their effect on the flow behavior. Acta Mater. 2014, 80, 1-15. [CrossRef]

22. Hansen, N. Cold deformation microstructures. Mater. Sci. Technol. 1990, 6, 1039-1047. [CrossRef]

23. Abdollah-Zadeh, A. The Investigation of Deformation, Recovery, Recrystallisation and Precipitation in Austenitic HSLA Steel Analogue Alloys. Ph.D. Thesis, University of Wollongong, Wollongong, Australia, 1996.

24. Torabinejad, V.; Zarei-Hanzaki, A.; Moemeni, S. An analysis to the kinetics of austenite recrystallization in Fe-30Mn-5Al steel. Mater. Manuf. Processes 2013, 28, 36-41. [CrossRef]

25. Hurley, P.J.; Hodgson, P.D.; Muddle, B.C. A study of deformation substructures in austenite using a model Ni- 30 wt.\% Fe alloy. Scr. Mater. 2001, 45, 25-32. [CrossRef]

(C) 2019 by the authors. Licensee MDPI, Basel, Switzerland. This article is an open access article distributed under the terms and conditions of the Creative Commons Attribution (CC BY) license (http:/ / creativecommons.org/licenses/by/4.0/). 